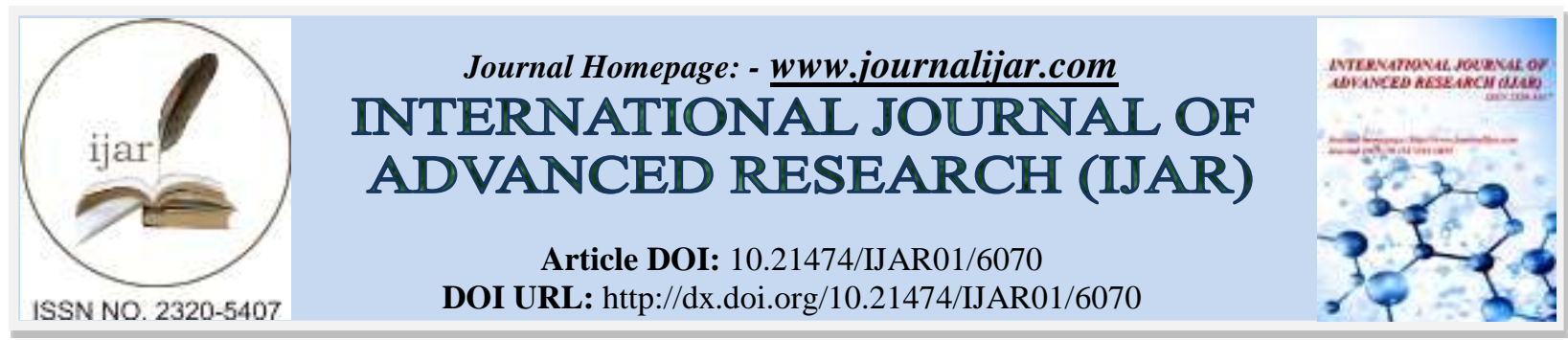

RESEARCH ARTICLE

\title{
IMPROVING RATE OF GBS SCREENING IN ANTENATAL PATIENT TO IMPROVE NEONATAL OUTCOME.
}

\begin{abstract}
Wasan adnan abduhameed.
High Institute of Infertility Diagnosis and Assisted Reproductive Technologies, Al-NahrainUniversity, BaghdadIRAQ.
\end{abstract}

\section{Manuscript Info}

Manuscript History

Received: 15 October 2017

Final Accepted: 17 November 2017

Published: December 2017

Key words:-

GBS screening, antenatal $\mathrm{t}$, neonatal outcome.

\section{Abstract}

Background: Group B-streptococcus is a kind of bacteria that can be present in the vagina of pregnant ladies with a liability to be inhaled by the neonate though its passage in the birth canal during labour with a possibility of neonatal mortality and morbidity ranges from simple RDS $^{*}$ to death, screening all pregnant women for the presence of GBS* help to improve neonatal outcome.

Objective: The study was planned to show the effect of group of Bstreptococcus on neonatal outcome in normal vaginal delivery.

Materials and methods: This is a prospective study counted on retrospective analysis (with ethical approval)in Al-Dhaid teaching hospital-Sharjah/UAE from June 2015 till October 2015. Swab from vagina and another from rectum is taken from all pregnant ladies attending antenatal care (1000 pregnant lady), swab from both sit placed into a selective (enrichmentbroth) media which encourage the growth of GBS. If bacteria growth in the broth it will be considered as positive.Urine test done to those in doubt of vagina GBS but negative test.So we divided the patient admitted through antenatal care to labour room to screened and unscreened patient and we compare the neonatal outcome of both. The pregnant women attend at 34-35 week and the swab is taken for culture and sensitivity those women are compared with other women attending to labour room or antenatal care without screening for a reason or another. Those with positive screening test covered with penicillin doses in the first stage of labour (8-10 hours)before labour.

Results:- In this study:

1. Incidences of screened patient are much higher than unscreened patient throughout the months

2. Incidence of hospital stay and receiving unnecessary antibiotics are much less in screened than unscreened

3. Financial burden in screened patient are much less than unscreened because of less hospital stay, less antibiotics use, less neonatal stay in SCABU

4. Our incidence of infected women among screened group is $25.7 \%$ 
5. $1-2 \%$ of neonatal got infected in unscreened compared to $0.02 \%$ in screened with $3 \%$ got complicated in unscreened ladies compared to $0.01 \%$ in screened.

Conclusion: Screening of GBS in pregnant ladies with antibiotics cover prior to labour by normal vaginal delivery reduce perinatal mortality and morbidity.

Copy Right, IJAR, 2017,. All rights reserved.

\section{Introduction:-}

Group B-streptococcus is a bacterial infection that can be found in a pregnant woman's vagina or rectum normally in about $25 \%$ of healthy adult women ${ }^{(1)}$. So those with positive GBS are called colonized but these bacteria can pass to the baby during delivery ${ }^{(2)}$, it affect 1 in 2000 babies in USA, but not all babies will become ill, but the outcome can be severe, some physicians adopt routine testing as part of prenatal care ${ }^{(1,2)}$. The CDC center of disease control and prevention recommend its routine screening to all pregnant women performed between $35^{\text {th }}$ and $37^{\text {th }}$ week of pregnancy i.e within 5 weeks of delivery by taking swab of both the vagina and the rectum for culture the result available within $24-48$ hours ${ }^{(3)}$.

American academy of pediatrics recommends that all women who have risk factor prior to being screened like preterm labour before 37 completed weeks to be treated with I.V antibiotics until their GBS status is established. Approximately 1 out of every 200 babies if not treated by antibiotics will develop signs and symptoms of GBS ${ }^{(4)}$.

GBS is not sexually transmitted disease if the test positive, or the patient is at high risk that include:

1. Labour or rupture membranes before 37 weeks,

2. Rupture membrane 18 hours before delivery,

3. Fever during labour,

4. UTI because of GBS streptococcus,

5. Previous baby with $\operatorname{GBS}^{(4,5)}$.

So if the test positive (according to CDC) and are not at high risk the chance of delivery a baby with GBS are

1. 1 in 200 if antibiotics are not given.

2. 1 in 4000 of antibiotics is given ${ }^{(1,2)}$.

Penicillin C (category B) is commonly used during pregnancy in non-allergic patient. During labour in normal vaginal delivery in cesarean delivery if labour not begun and or water have not broken the cesarean is not in need to be given antibiotics because 1 out of 200 babies can be ill. It is either early onset i.e signs and symptoms occurring within hours of delivery like sepsis, pneumonia, meningitis or breathing problems, heart and blood pressure instability, GIT and kidney problem ${ }^{(6)}$. While late onset GBS include:

1. Signs and symptoms within a week or a few months of delivery,

2. Meningitis is the most common symptoms ${ }^{(7)}$.

So:

Many women carry group B streptococcus naturally

Usually causes no problem, but can be devastating

Most common cause of serious infection in new born and meningitis in babies under 3 months

Most group B streptococcus infection in babies is preventable

Your knowledge can help protect your baby ${ }^{(4)}$

\section{Materials and methods:-}

In Al-Dhaid teaching hospital in the outpatient (antenatal care) held on Sunday and Wednesday about 40-60pregnant patient attend each time in different pregnant weeks of pregnancy. Those patients supposed to be screened (with ethical approval) by vaginal and rectal swab for GB streptococcus and then send to culture at 34 weeks gestation if they are positive they kept in computer in a special file number in red line so when they attend labour they supposed to be giventhe following regimens. 


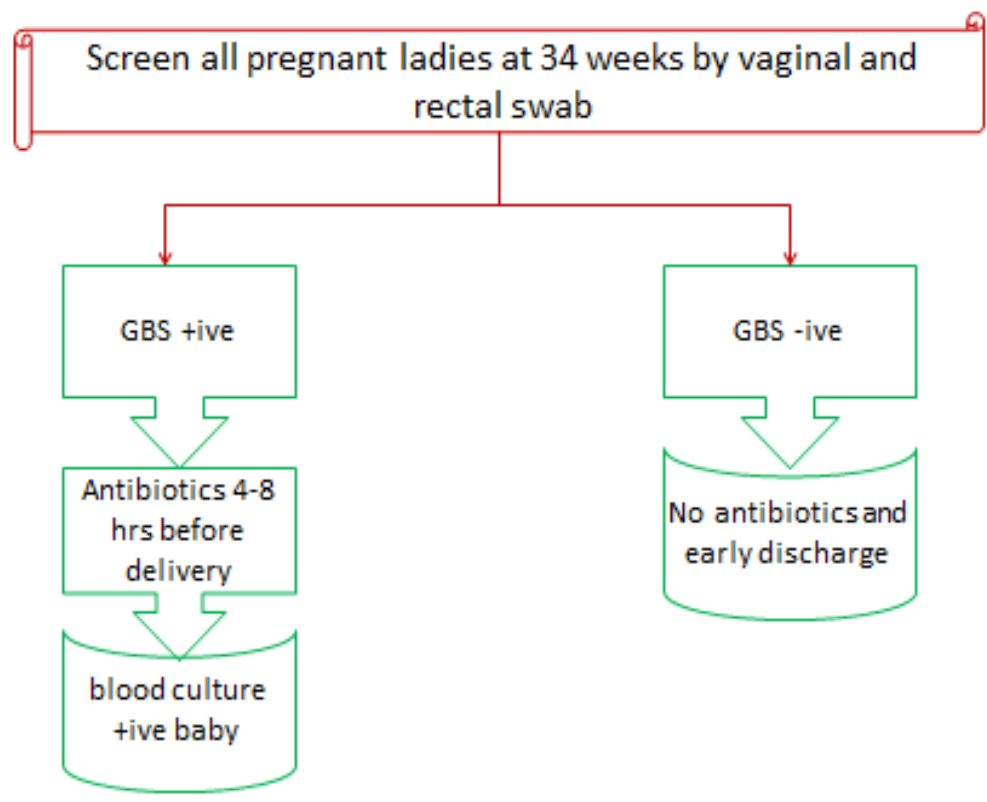

Figure 1:- Study design

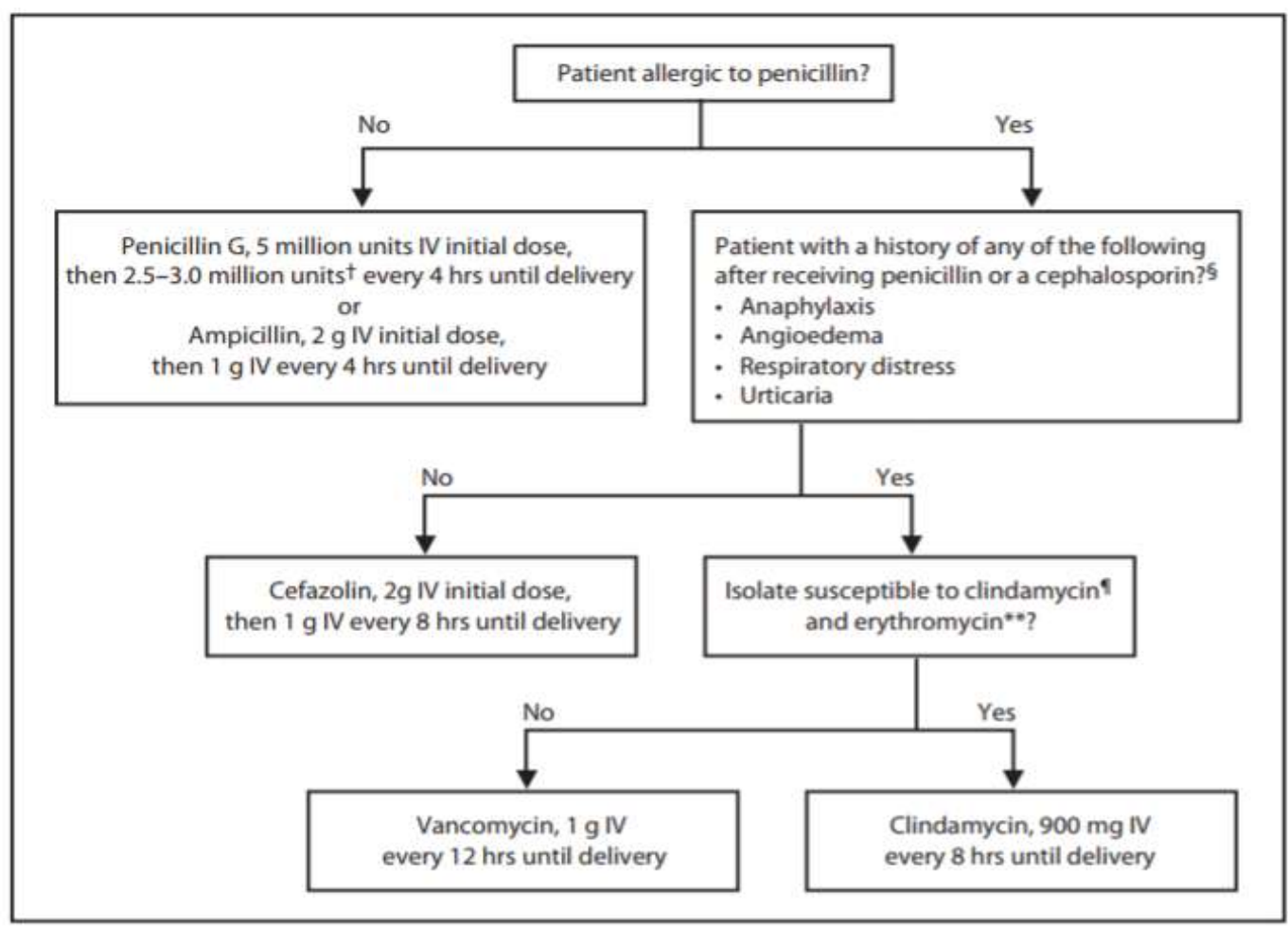

Figure 2:- Recommended regimes for intrapartum antibiotics

The patient need to be screened even if she planned to deliver by cesarean section because she had to be informed that if she positive need to be given treatment if she started labour with cervical dilatation or she developed rupture membrane.Those group of patient to be counted each month from June to October in 2015 and followed by in labour and their babies to evaluated from first hour of labour till 3 weeks later and compared with those attending antenatal care but not screened for financial reason or ignorance by the doctor or by the patient or lost in the laboratory or refused by the patient or those who attend directly to the labour room not through antenatal care also those patient to be followed after urgent GBS screen for those early and late neonatal outcome. 
The number of screened compared by unscreened each month. The total number of positive GBS from screened had been mentioned. The number of days of staying of those unscreened patients with total coast/patient had been screened /month. The neonatal outcome for those screened and unscreened had been compared. The number of GBS positive in unscreened also compared with GBS positive in screened patient.

\section{Rerults:-}

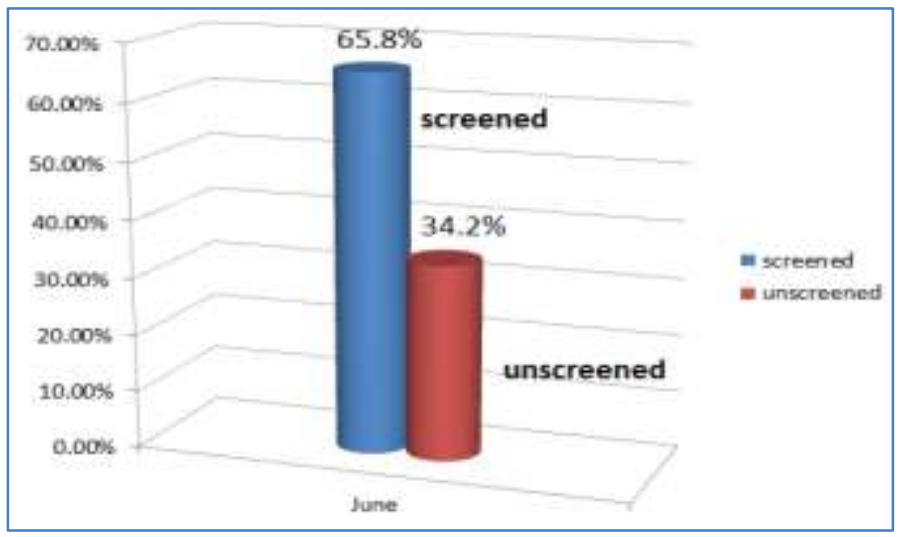

Figure 3:- Percentage of screened to unscreened in June

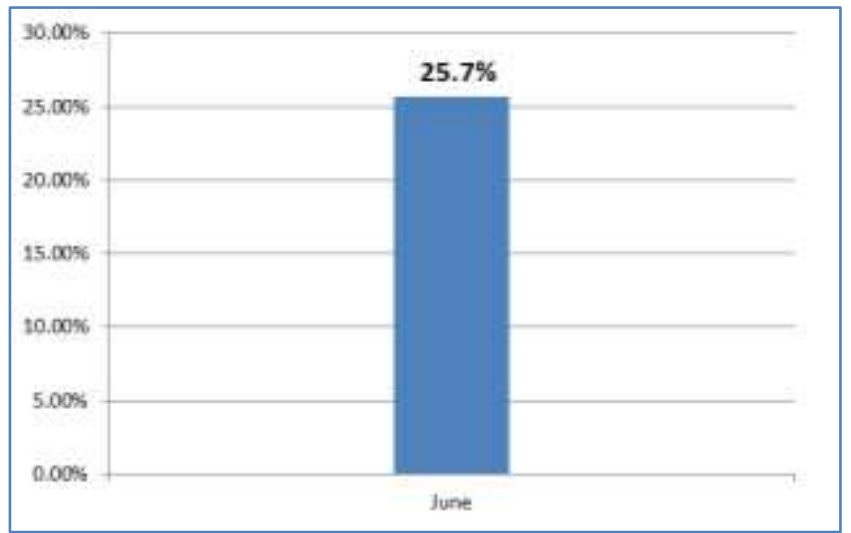

Figure 4:- Percentage of GBS +ve in screened patientsin June.

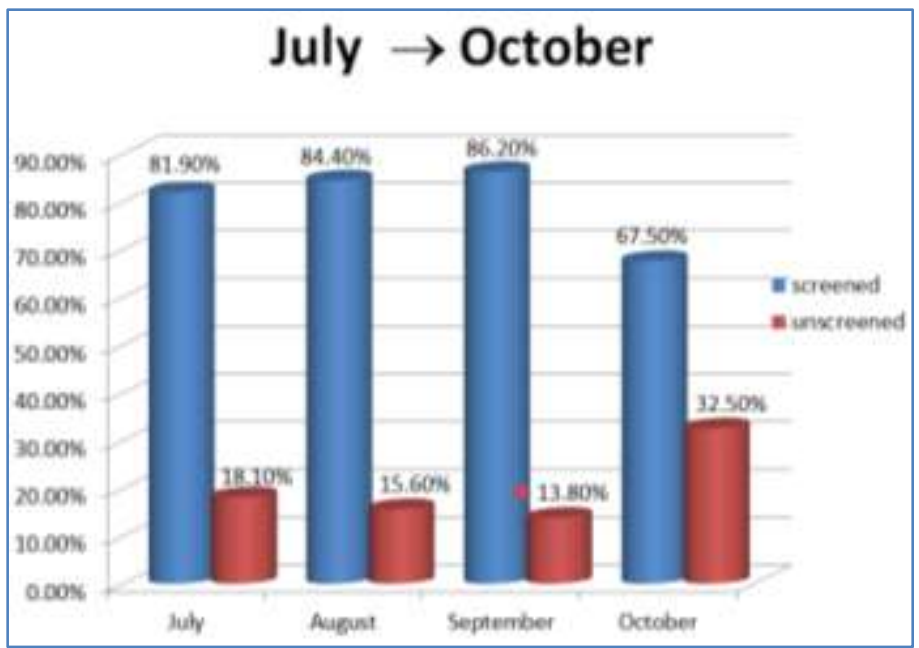

Figure 5:- Percentage of GBS +ve in screened patients from July to October. 


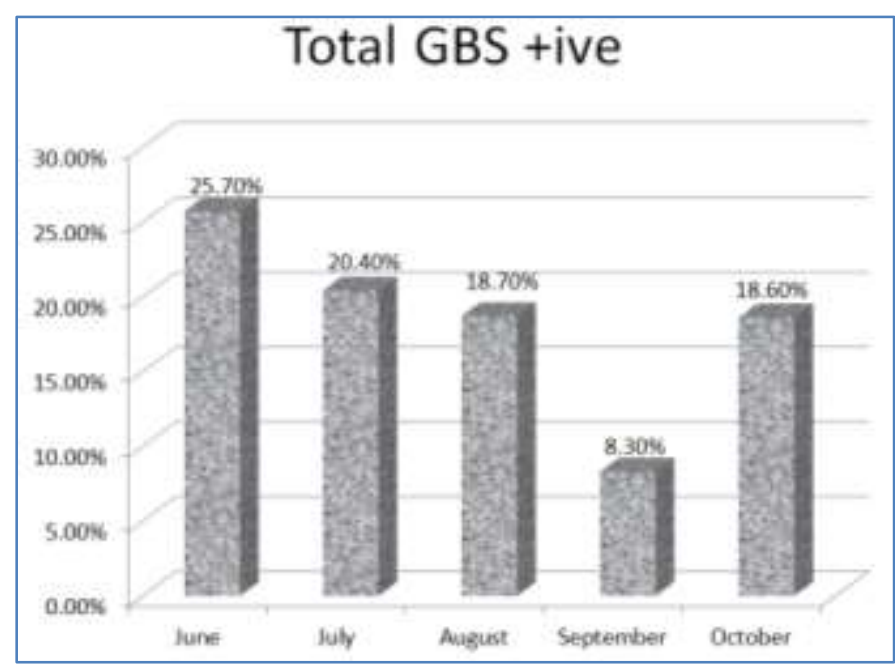

Figure 6:- Percentage of secerned to unscreened patients

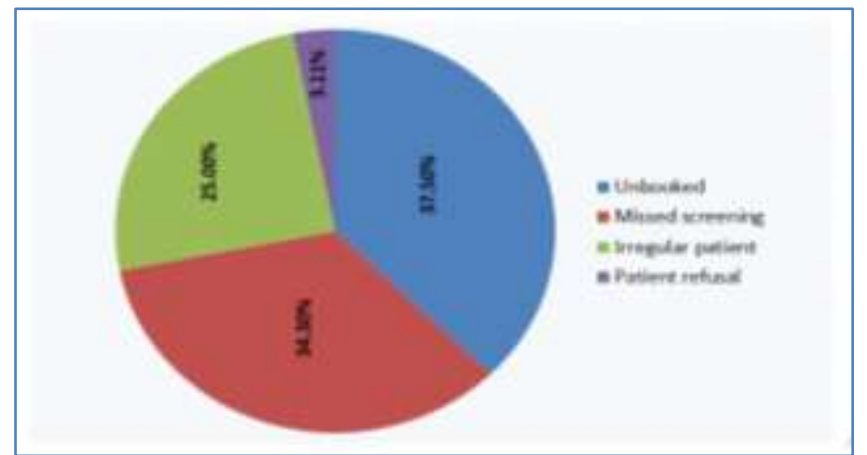

Figure 7:- Causes of unscreened patients

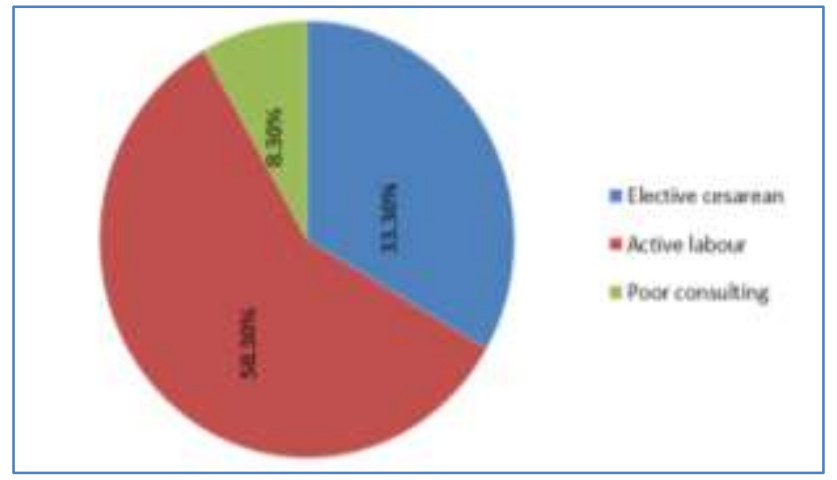

Figure 8:- Causes of unquote intrapartum prophylaxis $(<4 \mathrm{hrs})$ 


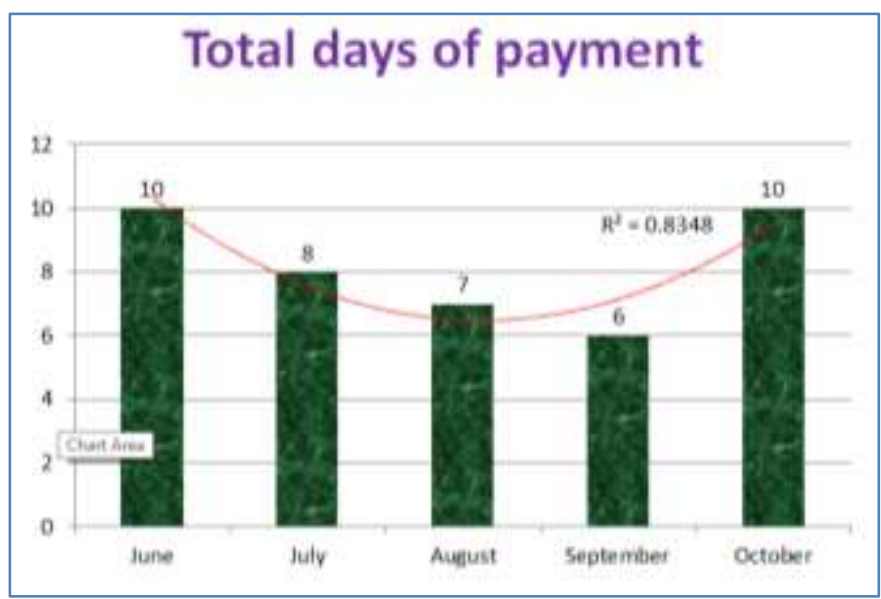

Figure 9:- total days of payment

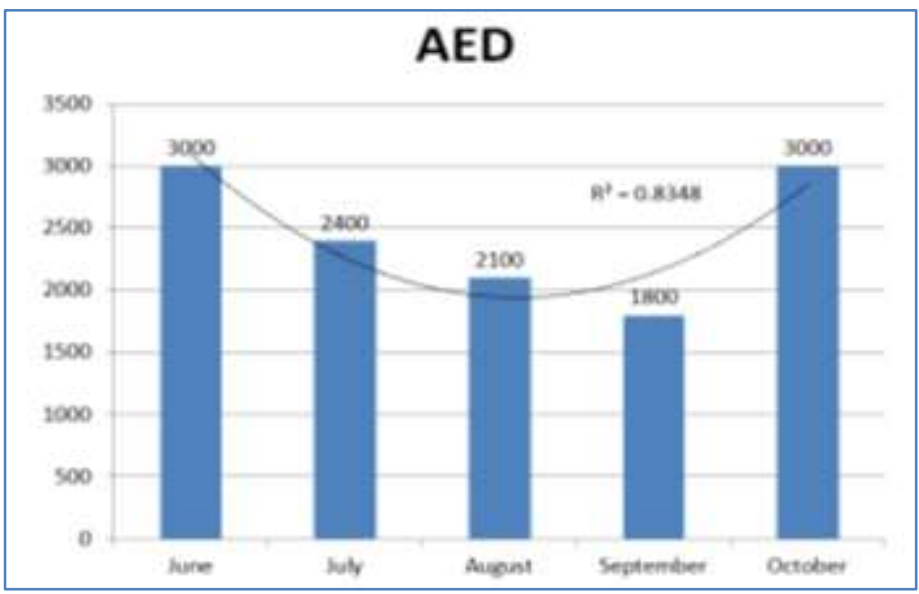

Figure 10:- Tatal days of payment

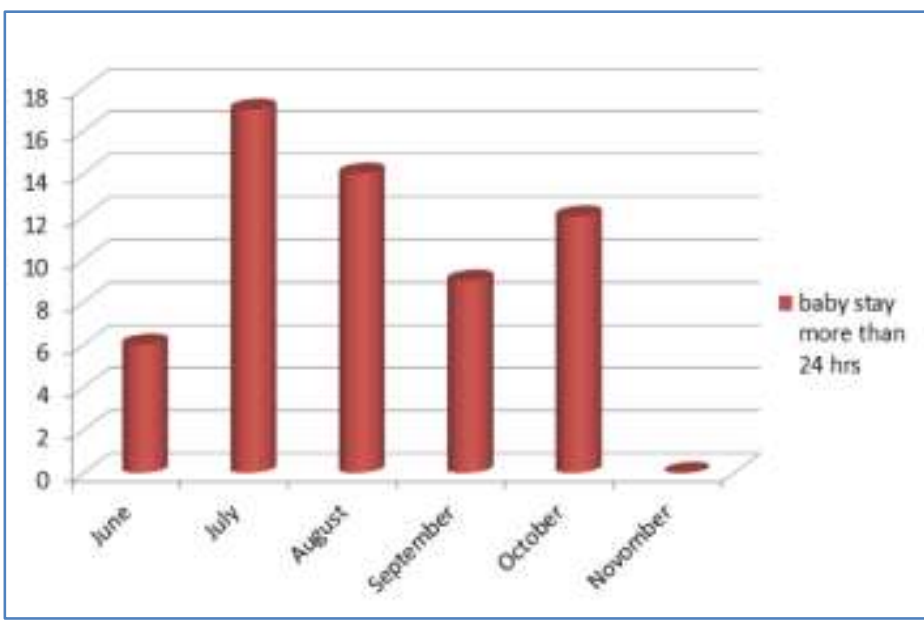

Figure 11:- Baby stay $>24$ hrs in the hospital

\begin{tabular}{|c|c|c|c|c|c|c|c|c|c|c|c|}
\hline Mo & Total & & Total no. of GBS & Total & Tot & No & $\%$ & Coa & Dou & SC & tota \\
nth & No. & & unscreened & no. of & al &. & of & st & ble & BU & 1 \\
201 & of & Total no. of & & mothe & no. & of & bab & PR & roo & & \\
5 & deliv & GBS & & & r & of & da & y & sing & m & \\
& ery & screened & & receiv & bab & ys & who & le & & & \\
\hline
\end{tabular}




\begin{tabular}{|c|c|c|c|c|c|c|c|c|c|c|c|c|c|c|}
\hline & & $\begin{array}{l}\text { PR } \\
\text { Mo } \\
\text { nth }\end{array}$ & $\begin{array}{l}\text { GBS } \\
\text { +ve }\end{array}$ & $\begin{array}{c}\text { Unscre } \\
\text { ened }\end{array}$ & $\begin{array}{c}\text { Unboo } \\
\text { ked }\end{array}$ & $\begin{array}{l}\text { GBS } \\
\text { +ve }\end{array}$ & $\begin{array}{c}\text { ed } \\
\text { antibio } \\
\text { tics }\end{array}$ & $\begin{array}{c}\text { ies } \\
\text { wh } \\
\text { o } \\
\text { stay } \\
>24 \\
\text { hr }\end{array}$ & $\begin{array}{c}\text { sta } \\
y\end{array}$ & $\begin{array}{c}\text { stay } \\
>24 \\
\text { hr }\end{array}$ & $\begin{array}{c}\mathrm{roo} \\
\mathrm{m}\end{array}$ & & & \\
\hline $\begin{array}{l}\mathrm{JU} \\
\mathrm{NE}\end{array}$ & 35 & 23 & 4 & 11 & 6 & 5 & 1 & 6 & 15 & $\begin{array}{l}25 . \\
7 \%\end{array}$ & $\begin{array}{c}3 \\
9 \mathrm{da} \\
\mathrm{ys} \\
450 \\
0\end{array}$ & $\begin{array}{c}3 \\
6 \text { day } \\
\text { s } \\
180 \\
00\end{array}$ & & $\begin{array}{c}630 \\
0\end{array}$ \\
\hline $\begin{array}{c}\text { JUL } \\
\mathrm{Y}\end{array}$ & 44 & 32 & 8 & 12 & 6 & 1 & 6 & 17 & 89 & $\begin{array}{l}20 . \\
4 \%\end{array}$ & $\begin{array}{c}5 \\
17 d \\
\text { ays } \\
850 \\
0\end{array}$ & $\begin{array}{c}12 \\
58 \mathrm{da} \\
\text { ys } \\
174 \\
00\end{array}$ & $\begin{array}{c}6 \\
14 d \\
\text { ays } \\
280 \\
0\end{array}$ & $\begin{array}{c}287 \\
00\end{array}$ \\
\hline $\begin{array}{c}\mathrm{AU} \\
\mathrm{G}\end{array}$ & 32 & 24 & 5 & 9 & 2 & 1 & 4 & 14 & 41 & & $\begin{array}{c}3 \\
15 d \\
\text { ays } \\
750 \\
0\end{array}$ & $\begin{array}{c}14 \\
27 \mathrm{da} \\
\mathrm{ys} \\
810 \\
0\end{array}$ & $\begin{array}{c}1 \\
14 d \\
\text { ays } \\
280 \\
0\end{array}$ & $\begin{array}{c}184 \\
00\end{array}$ \\
\hline SEP & 36 & 28 & 2 & 8 & 3 & 1 & 3 & 9 & 9 & & $\begin{array}{c}2 \\
18 d \\
\text { ays } \\
900 \\
0\end{array}$ & $\begin{array}{c}7 \\
21 \mathrm{da} \\
\text { ys } \\
630 \\
0\end{array}$ & & $\begin{array}{c}153 \\
00\end{array}$ \\
\hline $\begin{array}{c}\mathrm{OC} \\
\mathrm{T}\end{array}$ & 43 & 27 & 4 & 9 & 4 & 4 & & 14 & 14 & & & & & \\
\hline
\end{tabular}

Figure 12:- statistics

\section{Discussion:-}

According to what is mentioned in the introduction and what is mentioned in the results. We will found that from June 2015 till October 2015 we count total number of delivery in Al-Dhaid hospital ((300 patients) and we count the number of screened compared with unscreened (figure 3). From screened and unscreened patient, we count the number of GBS positive patient (figure 4) (note) unscreened patient we urgently expose to vaginal and rectal swab when they are in the labour and they are given prophylactic penicillin according to the regimen at least 4 hours before delivery (figure 2) and those patients to be kept in the hospital 2 to 3 days till the result received and the baby kept in the neonatal care unit with prophylactic antibiotics till the result appear (figure 1). Those whom are unscreened patient we evaluate the neonatal outcome in those GBS positive and not received antibiotics the incidence of neonatal mortality and morbidity evaluated. After following the babies till 3 weeks after delivery to test for latecomplication(figure 1).

We found that from all the GBS positive babies $2 \%$ got infected, $0.5 \%$ got complicated with different kinds of complication starting from encephalitis to simple flue like illness when those infected patients received antibiotics for $2 \%$ whom are infected only $0.02 \%$ got complicated. So this drop in incidence of complications after discovering the problem and receiving antibiotics. Is the goal of this study?

In this study we discuss and screen of the reasons behind unscreened patient (figure 7, figure 8) and we found that those are the main reason which we try to find solution for each next year to reduce neonatal mortality and morbidity.

1. Lack of knowledge of pregnant women about the need of GBS

2. False negative results

3. Irregular antenatal visit and unbooked patient

4. Patient not complaint and refuse screening

5. Low physician to patient ratio 
6. Lack of antenatal education sessions

7. Poor follow up by physician and nurses to the result of culture

8. Not taking prophylaxis antibiotics

9. Staffis not adapted to GBS screening and forgets it

10. It was previously not group work

11. Financial reason because of extra coast of test and treatment

12. Some are preterm labour

So we put a goal to reduce the incidence of unscreened patient to $15 \%{ }^{(8)}$ by the end of December 2015 and the strategic plan to do so is:

1. Revise and update the current guidelines related GBS screening and treatment

2. Prepare and conduct awareness sessions related GBS screening to all pregnant women as per American reference.

3. Send circular to all obs./gyn. physician related to guidelines and critical result

4. Update circular to all concerned department [pediatric, lab. maternity, outpatient, labour room]

5. Emphasize on preparing the staffing pattern related to patient ratio

6. Data collection on months basis and we distribute the responsibilities and put time line to reach the goal ${ }^{(9)}$.

\section{Conclusion and recommendation:-}

At the end we want to recommend that all antenatal care patient need to be screened to reduce the incidence of neonatal infection by GBS positive patient which will reduce neonatal mortality and morbidity whether in normal vaginal delivery or urgent cesarean section after rupture membrane cervical dilatation or those preterm labour. Those patients to be educated early in pregnancy for the importance of this test, also this test supposed to be available by general government hospital with availability of penicillin medication. All obstetric and neonatal unit should adept the GBS screen protect ${ }^{(9,10)}$.

It supposed to be followed and updated

\section{References :-}

1. Cunningham F, Gary et al. Williams's obstetrics. Control and prevention twenty second Ed.; ch.58.

2. CDC.Prevention in newborns. US centers for disease control and prevention 2016.

3. Verani J, Jennifer R et al.Prevention of perinatal group B streptococcal disease. Morbid and Mort weekly2010; report 59 (RRIO): 1-32

4. ACOG, 2015g. Group B streptococcus and pregnancy. American college of obstetrics and gynecology (Accessed December-2016)

5. Gibbs RS et al. Perinatal infections die to group B streptococcus infection.Obst and Gyn2004;104 (5pt 1): 106276

6. Valkenbury-Van den Berg Aw et al. Association between colonization with group B streptococcus and preterm delivery. A systemic review. Actaobstetricset Gynecological Scandinavic2009. 88 (9): 958-67

7. Daniels J et al 2009. Rapid testing for group B streptococcus during labour. A test accuracy study with evaluation of acceptability and coast-effectiveness. Health technology assessment 13 (42): 1-154

8. NICE. 2012. Neonatal infection (early onset): antibiotics for prevention and treatment. National institute for health and care. Excellence, clinical guideline, 149. www.Nice.Org. u/s (accessed January 2017)

9. Ohisson A, Shah VS. 2014. Intrapartum antibiotics for known maternal group B streptococcal colonization, Cochrane database of systemic reviews (6) CD 007467. Online libraryWile.com (January 2017)

10. RCOG. 2013. Information for you: group B streptococcus (GBS)infection in newborn babies. Royal college of Obstetrics and Gynecologists. www.rcog.org.uk (2017). 